\title{
GC-MS and FT-IR analysis of the bio-oil with addition of ethyl acetate during storage
}

\section{Le Zhang, Chenjie Shen and Ronghou Liu*}

Biomass Energy Engineering Research Centre, School of Agriculture and Biology, Shanghai Jiao Tong University, Shanghai, China

Edited by:

Jalel Labidi, University of the Basque

Country, Spain

\section{Reviewed by:}

Rajbir Singh Sangwan, Université de

Picardie Jules Verne, France

Suyin Gan, The University of

Nottingham Malaysia Campus,

Malaysia

${ }^{*}$ Correspondence:

Ronghou Liu, Biomass Energy

Engineering Research Centre, School of Agriculture and Biology, Shanghai

Jiao Tong University, 800 Dongchuan

Road, Shanghai 200240, China

e-mail: liurhou@sjtu.edu.cn
Different mass fractions $(0,3,6,9,12$, and $15 \%)$ of ethyl acetate were added to bio-oil for improving its storage stability during storage at $40^{\circ} \mathrm{C}$ for 35 days. For different bio-oils during storage, physical properties were characterized and chemical components were determined by GC-MS and FT-IR. The results of properties characterization showed that, addition of ethyl acetate could instantly lower bio-oil viscosity, water content, and dramatically decrease the rate of aging. $\mathrm{pH}$ value of bio-oil can be instantly improved by adding ethyl acetate. GC-MS results revealed that addition of various content of ethyl acetate into bio-oil and its storage at $40^{\circ} \mathrm{C}$ for 35 days could both lead to disappearance of previous compounds and generation of new compounds. FT-IR results showed that addition of various content of ethyl acetate into bio-oils and its storage at $40^{\circ} \mathrm{C}$ for 35 days could slightly change the wavenumbers of substantial functional groups in bio-oils.

Keywords: bio-oil, ethyl acetate, physical properties, GC-MS, infrared spectrum

\section{INTRODUCTION}

Shortage of fossil fuels and environmental pollution lead to a great interest in using renewable resources of energy (Mohan et al., 2006). Biomass energy is a clean, environment-friendly renewable energy. Recently, producing bioenergy such as bio-oil, fuel gas, and bio-char through fast pyrolysis has been a hot spot globally. The liquid product of fast pyrolysis, bio-oil, has several advantages compared to petroleum fuels. But the storage instability of fast pyrolysis bio-oil is a big problem for its direct application in thermodynamic combustion engines (Oasmaa and Kuoppala, 2003; Kim et al., 2012).

The instability of bio-oil can be illustrated as follows. Biooil usually has substantial chemical compounds such as phenols, ketones, acids, aldehydes, alcohols, ethers, and esters (Oasmaa et al., 2001), which lead to production of new compounds with higher molecular weight through esterification, polymerization, etc. During storage process of bio-oil, several physical properties, that is, viscosity, water content, etc., increase with the extension of the storage period (Diebold et al., 2000). Also, the $\mathrm{pH}$ value will decrease slowly. The chemical components of bio-oil are also changed due to the various complicated chemical reactions. Thus, the storage stability of bio-oil can be evaluated by investigating the changes of bio-oil viscosity, water content, $\mathrm{pH}$, and chemical components.

In order to improve the physiochemical properties and storage stability of pyrolysis bio-oil, addition of organic solvents was proposed and investigated (Diebold and Czernik, 1997; Theissen, 2009). In the previous studies, Boucher et al. (2000) demonstrated that methanol could improve stability of bio-oil and exhibited the best effect at the addition proportion of $10 \mathrm{wt} \%$. Pidtasang et al. (2013) investigated the influence of alcohol on the properties and storage stability of bio-oil, and found that the stability, viscosity, and heating value of bio-oil could be improved by adding a small proportion (2.5-10\%) of alcohol. Wu (2011) studied the effect of different fraction of methyl acrylate on pyrolysis bio-oil during storage at $40^{\circ} \mathrm{C}$ for 42 days and demonstrated that methyl acrylate had significant influence on improvement of bio-oil stability. All the previous researches consistently revealed that adding proper organic solvents could improve the properties and storage stability to an extent. However, to the best of our knowledge, the effect of ethyl acetate on physiochemical properties and storage stability of pyrolysis bio-oil during long-term storage period was seldom reported.

Thus, in the current work, effect of different mass fractions ( 0 , $3,6,9,12$, and $15 \%$ ) of ethyl acetate on bio-oil storage stability was investigated during storage at $40^{\circ} \mathrm{C}$ for 35 days. For all bio-oil samples in storage experiment, physical properties (viscosity, water content, and $\mathrm{pH}$ ) were tested and chemical components were characterized using GC-MS and FT-IR. According to statistical results, several conclusions were drawn, which could provide technical support for the application of pyrolysis bio-oil from biomass.

\section{MATERIALS AND METHODS \\ BIO-OIL}

The bio-oil used in current research was derived from the fast pyrolysis of sawdust at $500^{\circ} \mathrm{C}$ in a fluidized-bed reactor. After production, the crude bio-oil was stored in sealed glass bottles in a freezer at $4^{\circ} \mathrm{C}$ before using it in the experiment. Liu et al. (2011) investigated the process of fast pyrolysis of rice husk to produce bio-oil in a fluidized-bed reactor and analyzed the physical-chemical properties of the pyrolysis bio-oil.

\section{STORAGE EXPERIMENT}

For the storage experiments, six bio-oil samples with different content $(0,3,6,9,12$, and 15\%) of ethyl acetate were used. Each experiment was repeated for four times and the results were 
averaged. The standard errors were calculated and presented in the figures. All the samples had the same total volume of bio-oil for $50 \mathrm{~mL}$ and were stored in sealed reagent bottles with a total volume of $150 \mathrm{~mL}$. All the samples of treatment group were stored at $40^{\circ} \mathrm{C}$ for 35 days. During the storage period, the properties of bio-oils, including water content, viscosity, $\mathrm{pH}$, were determined at specific time $(0,7,14,21,28,35$ days $)$. When storage time was between 0 and 35 days, all the samples were tested using GC-MS and FT-IR.

\section{ANALYSIS METHODS \\ Viscosity}

According to ASTM D445, the viscosity of bio-oil was tested using a petroleum products' kinematic viscosity tester purchased from Shanghai Changji Geological Instrument Co., Ltd., type SYD-265H. All the samples were analyzed for viscosity at $40^{\circ} \mathrm{C}$.

\section{Water content}

According to ASTM E203, the water content of bio-oil sample was tested using Karl-Fischer titration purchased from Metrohm Instrument Co., Ltd., type KFT 870.

\section{pH value}

According to the $\mathrm{pH}$-potentiometer method, the $\mathrm{pH}$ value of biooil sample was determined using a $\mathrm{pH}$ meter purchased from Shanghai Leici Instrument Plant, type PHS-3C.

\section{GC-MS}

Chemical composition of bio-oil was tested by GC-MS (AutoSystem XL GC/TurboMass MS, Perkin Elmer) with a quadruple detector and a DB-1MS capillary column $(30 \mathrm{~mm} \times 0.25 \mathrm{~mm}$ inner diameter $\times 0.25 \mu \mathrm{m}$ thickness). Helium (UHP) was used as the carrier gas with a constant flow of $1.2 \mathrm{~mL} / \mathrm{min}$. The initial temperature of oven temperature program was set at $40^{\circ} \mathrm{C}$ and continued for $4 \mathrm{~min}$, rising by $5^{\circ} \mathrm{C} / \mathrm{min}$ to $250^{\circ} \mathrm{C}$, which continued for $10 \mathrm{~min}$. The injector temperature was $250^{\circ} \mathrm{C}$. The volume of injected sample ( $10 \%$ of bio-oil in chloroform) was $1 \mu \mathrm{L}$. Electron ionization (EI) was used in the MS and standard mass spectra with $70 \mathrm{eV}$ ionization energy were recorded with a scanned range from 0 to $1200 \mathrm{amu}$. The computer matching of mass spectra was performed using the NIST98 and WILEY7.0 library and the retention times of known species injected in the chromatographic column were used for identification of the peaks.

\section{FT-IR}

The FT-IR analysis of bio-oil was carried out using Fourier infrared and Raman spectrometer purchased from Bruker Company, type EQUINOX 55.

\section{RESULTS AND DISCUSSION INFLUENCE OF ETHYL ACETATE ON VISCOSITY $\left(40^{\circ} \mathrm{C}\right)$, WATER CONTENT, AND PH VALUE OF BIO-OIL}

Figure 1 shows the change of (1) viscosity $\left(40^{\circ} \mathrm{C}\right)$, (2) water content, and (3) $\mathrm{pH}$ value of bio-oil during storage for 35 days. The standard errors estimation in the measured readings was given in the figures. According to the standard errors estimation, a conclusion could be drawn that accuracy and repeatability of the experiments were well.

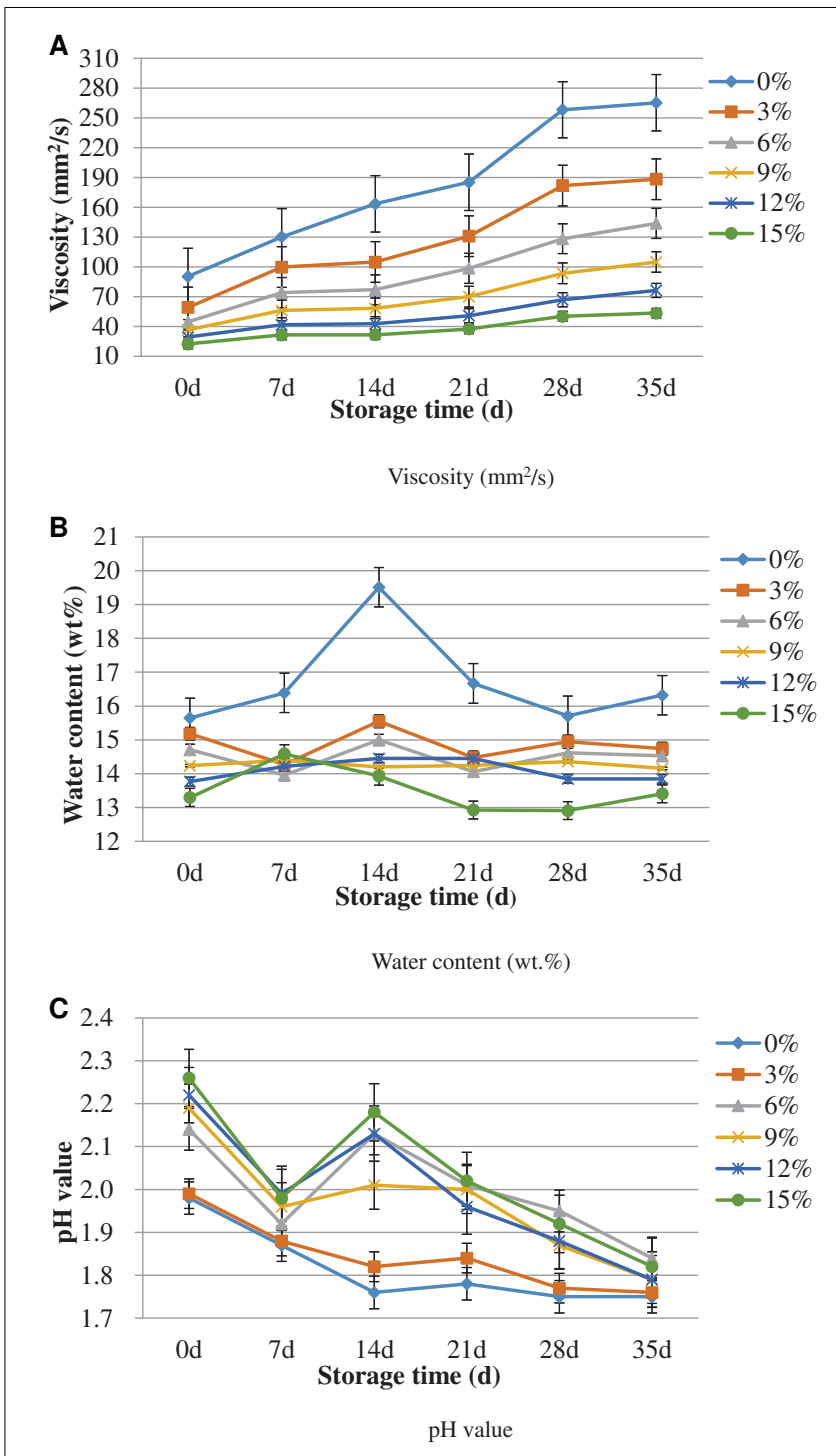

FIGURE 1 |The change of (A) viscosity $\left(40^{\circ} \mathrm{C}\right)$, (B) water content, and (C) $\mathrm{pH}$ value of bio-oil during storage for 35 days

Viscosity is a significant property for pyrolysis bio-oil as combustion fuel because it affects injecting and pumping of liquid fuel. In addition, viscosity is one of the most important indicators of bio-oil storage stability (Oasmaa and Meier, 2005). According to Figure 1A, at any time point of the whole storage process, all the bio-oil samples with different fractions of ethyl acetate had lower viscosity than blank sample $(0 \%)$ and the more the additive content is, the lower the bio-oil viscosity will be. The results indicated two points. First, the addition of ethyl acetate could instantly lower viscosity of bio-oil to a certain degree. Second, the addition of ethyl acetate to bio-oil had the very beneficial effect of decreasing the rate of aging. During whole storage period, the viscosity of any individual bio-oil sample increased gradually with the extension of the storage period due to aging reactions of reactive organic compounds in bio-oil. The reactions such as polymerization and polycondensation reactions (Fahmi et al., 2008; Lu et al., 2008) 
would lead to larger molecules, which consequently would cause an increase in viscosity of bio-oil (Diebold and Czernik, 1997). Recently, many related researches were performed to decrease viscosity of bio-oil. In the work of Pattiya and Suttibak (2012), a hot vapor filter was used to filter pyrolysis bio-oil and demonstrated that the filtered bio-oil appeared to have a better stability and lower initial viscosity. Bridgwater (2012) reported that bio-oil viscosity increased slowly after production due to secondary reactions including polymerization and proposed a number of ways to upgrade bio-oil, such as solvent addition, emulsions, catalytic upgrading, etc.

The water content of bio-oil is another indicator of storage stability (Oasmaa and Meier, 2005). In general, water in bio-oils came from two aspects: the original moisture in the feedstock and the dehydration reactions occurring during the pyrolysis process (Moreira et al., 2013). As shown in Figure 1B, at the beginning of storage process ( 0 day), the addition of various content of ethyl acetate could consistently lower water content of bio-oil samples to a certain extent. Also, the more ethyl acetate was added, the lower water content would be. This can be explained as follows. The addition of ethyl acetate could instantly decrease bio-oil water content through dilution effect because the additive was known to have no water content. During the long-term storage period, the change of bio-oil water content was negligible. This indicated that the chemical reactions, which consume and produce water could not significantly change the water content. Similarly, Kim et al. (2012) investigated effect of storage duration on bio-oil properties and demonstrated that change in water content of bio-oil was negligible during the storage at $23^{\circ} \mathrm{C}$ for 10 weeks. Generally, pyrolysis bio-oil has higher water content than petroleum, which could lead to lower heating value and lower viscosity, which indicated the negative and positive effect. According to Vamvuka (2011), during the biomass pyrolysis process, there are many reactions that can generate water, such as dehydration reaction, heterogeneous reaction, and aromatization reaction. Thus, it is difficult to control water content of bio-oil by controlling reactions due to its complexity. Some related researches reported several methods to lower the water content of bio-oil, for instance, treatment for biooils with ethyl alcohol (Oasmaa et al., 2004), usage of fractional condensation (Yin et al., 2013), appropriate selection of biomass materials (Chen et al., 2010), etc.

Generally, due to existence of substantial amounts of organic acids such as acetic and formic acid, etc., the $\mathrm{pH}$ value of pyrolysis bio-oil is about 2.0-4.0 (Liu et al., 2011). The high acid number leads to high corrosiveness in vessels and pipework (Bridgwater, 2012). Thus, it is significant to improve $\mathrm{pH}$ value of pyrolysis biooil before being used. Figure 1C shows the change of $\mathrm{pH}$ value of bio-oil during storage for 35 days. From Figure 1C, it can be seen that $\mathrm{pH}$ value of bio-oil can be instantly improved by adding ethyl acetate. Compared to the blank sample (0\%), the $\mathrm{pH}$ values of biooil samples $(3,6,9,12,15 \%)$ were increased through ethyl acetate addition by $0.50,8.08,10.61,12.12$, and $14.14 \%$, respectively, at the beginning of storage ( 0 day). At the end of storage ( 35 days), the growth rates were $0.57,5.14,2.29,2.29$, and $4.00 \%$, respectively. During the whole storage process, the change tendency of $\mathrm{pH}$ was descending. This may be because of the decomposition of ethyl acetate and formation of acetic acid, which increase the acid number of bio-oil. In addition, according to Kim et al. (2012), the $\mathrm{pH}$ value did not change significantly during the storage period at $23^{\circ} \mathrm{C}$ for 10 weeks. It was also reported that careful materials selection could acquire pyrolysis bio-oil with better quality (Bridgwater, 1999).

\section{GC-MS ANALYSIS OF BIO-OILS}

The pyrolysis bio-oil was a complicated mixture containing substantial kinds of chemical compounds (Chen et al., 2011). The blank sample ( 0,35 days) and other samples $(3,6,9,12,15 \%)$ at 35 days were determined by GC-MS. Table 1 shows GC-MS analysis of bio-oils with different content of ethyl acetate. Only the compounds with relative concentration higher than $0.02 \%$ are listed in Table 1.

According to Table 1 (see relative content (\%)), it could be calculated that $22,22,24,21,23,20,20$ kinds of chemical compounds including phenols, acids, ketones, furans, etc., were determined by GC-MS for biooils with $0 \%$ ( 0 day), $0 \%$ (35 days), 3\% (35 days), 6\% (35 days), 9\% (35 days), 12\% (35 days), 15\% (35 days) ethyl acetate, respectively. For the blank sample, some abundant compounds were easily detected, such as pyrocatechol, lysidine, 5-methyl-2-furfural, ethyl-2-oxo propanoate, etc. After addition of various content of ethyl acetate, there were some new high polymers existing in bio-oil samples, such as guaiacol, 2-methoxy-4-propenyl-phenol, 4-hydroxy3-methoxyphenylacetone, etc. Results of blank sample ( $0 \%, 0$ day) and blank sample $(0 \%, 35$ days $)$ indicated that storage at $40^{\circ} \mathrm{C}$ for 35 days could lead to disappearance of previous compounds and generation of new compounds. This was probably due to the aging reactions of chemical compounds in bio-oils (Hilten and Das, 2010). Also, addition of various content of ethyl acetate could bring about loss of earlier compounds and production of different compounds. This is probably because ethyl acetate added into bio-oils participated in the aging reactions. Besides, existence of lots of oxygenated compounds was demonstrated according to formula of chemical compounds, which was a direct cause of rather low heating value of pyrolysis bio-oil (Liu et al., 2009). In recent years, new technique for identification of chemical components in bio-oil was investigated widely. For instance, comprehensive two-dimensional gas chromatography was used by Tessarolo et al. (2013) to identify chemical components of two bio-oil samples derived from flash pyrolysis using empty palm fruit bunch and pine wood chips, and demonstrated existence of primary classes of compounds such as cyclopentenones, ketones, furans, furanones, phenols, sugars, etc. In the work of Marsman et al. (2008), identification and classification of components in flash pyrolysis bio-oil and hydrodeoxygenated bio-oils were performed using two-dimensional gas chromatography and time-of-flight mass spectrometry, which is a useful and fast technique to determine the composition of pyrolysis oil. Thus, in order to acquire more detailed information on components of bio-oil, the characterization of pyrolysis bio-oil from sawdust using two-dimensional gas chromatography is our next work.

\section{FT-IR ANALYSIS OF BIO-OILS BEFORE AND AFTER STORAGE FOR 35 DAYS}

FT-IR spectroscopy is a powerful analytical technique to characterize the functional groups of pyrolysis bio-oils (Lievens et al., 
No. Name
Formula

\begin{tabular}{lllllll}
\hline $0 \%$ & $0 \%$ & $3 \%$ & $6 \%$ & $9 \%$ & $12 \%$ & $15 \%$ \\
$(0$ day $)$ & $(35$ days $)$ & $(35$ days $)$ & $(35$ days $)$ & $(35$ days $)$ & $(35$ days $)$ & $(35$ days $)$
\end{tabular}

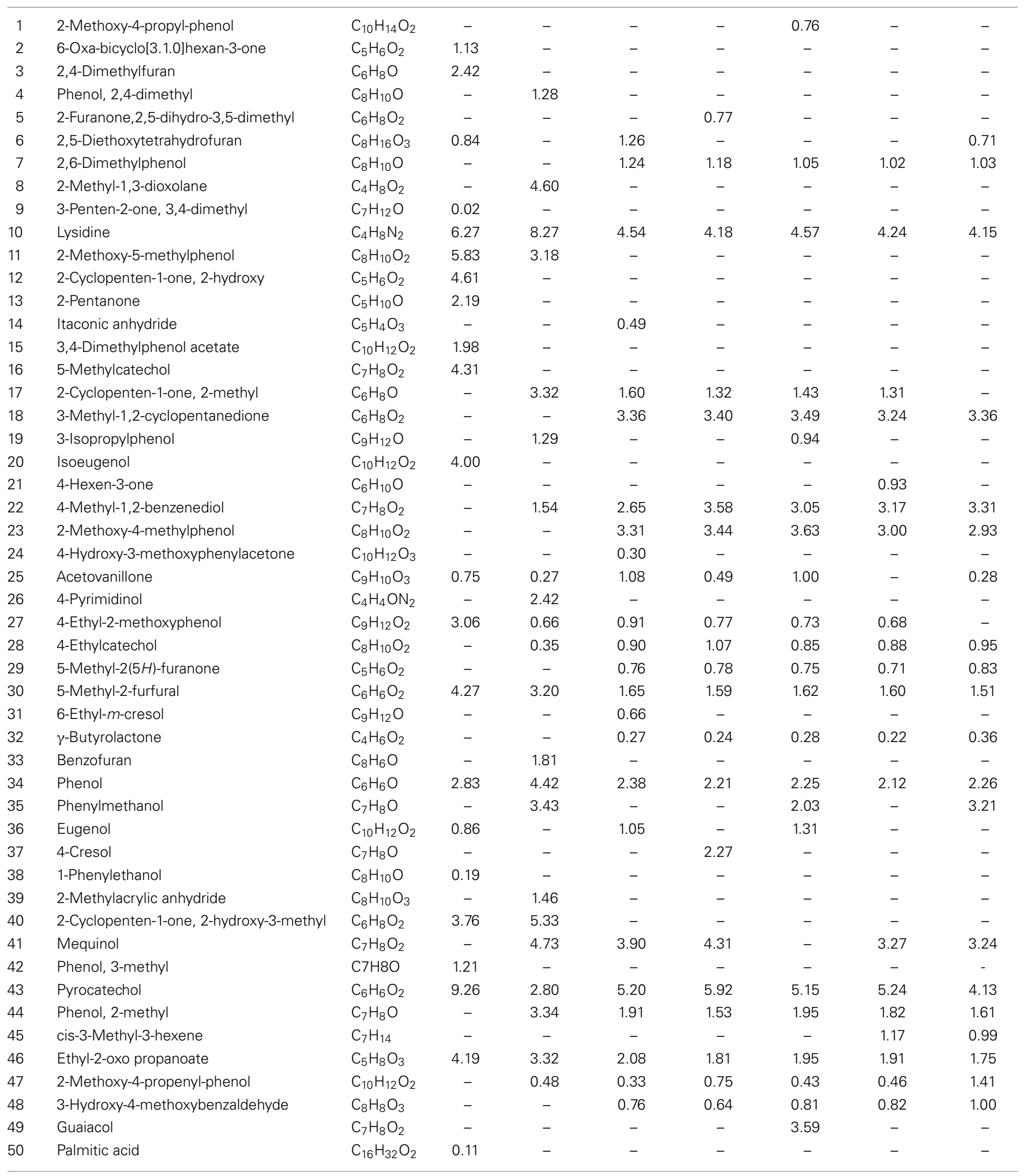

- , means not detected. 


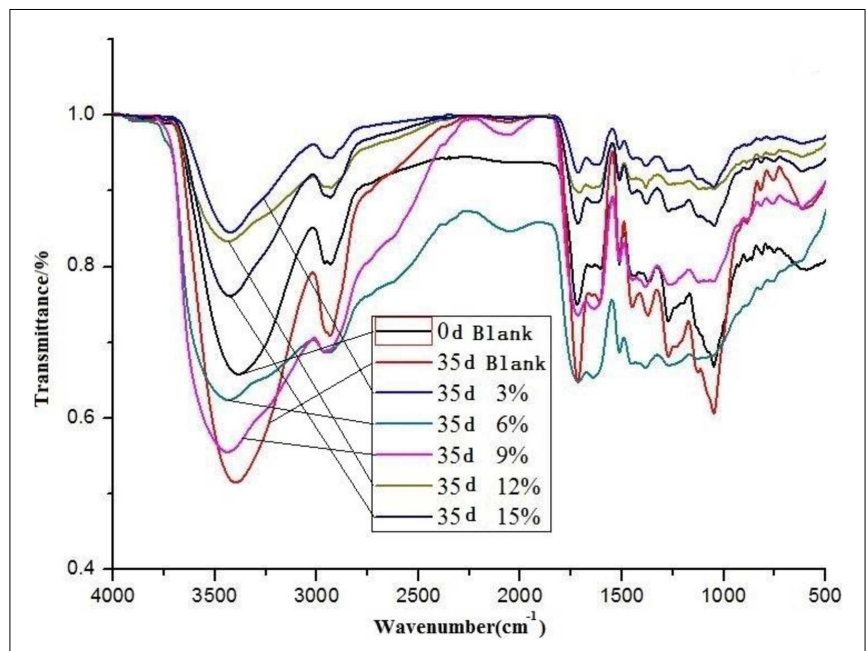

FIGURE 2 |The infrared spectra of bio-oil samples with different content of ethyl acetate.

2013). Using variation information on functional groups of different bio-oil samples, the discrepancy of chemical components of various bio-oil samples could be deducted. The infrared spectra of bio-oil samples with different content of ethyl acetate are listed in Figure 2.

According to Figure 2, wavenumbers of substantial functional groups in bio-oil were between 3000 and $3500 / \mathrm{cm}$ as well as between 1000 and $1750 / \mathrm{cm}$, which indicated the existence of $\mathrm{C}=\mathrm{O}$ bonds, $\mathrm{C}=\mathrm{C}$ bonds, $\mathrm{C}-\mathrm{O}$ bonds, $\mathrm{C}-\mathrm{H}$ bonds, and $\mathrm{O}-\mathrm{H}$ bonds, etc. in bio-oil. These functional groups demonstrated that there were alcohols, phenols, aromatics, and acids, etc. in bio-oil, which demonstrated the consistent results obtained from GC-MS results. Recently, a study (Lievens et al., 2011) reported that FT-IR spectra of bio-oil in the region of $1490-1850 / \mathrm{cm}$ could provide detailed information on various carbonyl groups in bio-oil. It is well known that biomass consists of cellulose, hemicellulose, and lignin, which are totally CHO chemical compounds (Chen et al., 2010). In addition, from Figure 2, conclusion can be drawn that addition of various content of ethyl acetate into bio-oils and the storage at $40^{\circ} \mathrm{C}$ for 35 days could slightly change the wavenumbers of substantial functional groups in bio-oils, which showed that aging reactions occurred during the storage period and ethyl acetate participated in the chemical reactions in bio-oil.

\section{CONCLUSION}

(1) The addition of ethyl acetate could instantly lower viscosity of bio-oil to an extent and decrease its rate of aging.

(2) The addition of various content of ethyl acetate could consistently lower bio-oil water content to a certain extent. And, the more ethyl acetate was added, the lower water content would be.

(3) $\mathrm{pH}$ value of bio-oil can be instantly improved by adding ethyl acetate.

(4) GC-MS results revealed that addition of various contents of ethyl acetate and storage at $40^{\circ} \mathrm{C}$ for 35 days could both lead to disappearance of previous compounds and generation of new compounds.

(5) FT-IR results indicated that addition of various contents of ethyl acetate and storage at $40^{\circ} \mathrm{C}$ for 35 days could slightly change the wavenumbers of substantial functional groups in bio-oils.

\section{ACKNOWLEDGMENTS}

Financial support from the National Science and Technology Supporting Plan through contract (Grant No.2011BAD22B07) are greatly acknowledged. In addition, Daniel L. Brown from the University of Southampton, UK is greatly acknowledged for his valuable suggestions and correction of the manuscript.

\section{REFERENCES}

Boucher, M. E., Chaala, A., Pakdel, H., and Roy, C. (2000). Bio-oils obtained by vacuum pyrolysis of softwood bark as a liquid fuel for gas turbines. Part II: stability and ageing of bio-oil and its blends with methanol and a pyrolytic aqueous phase. Biomass Bioenergy 19, 351. doi:10.1016/S0961-9534(00)00044-1

Bridgwater, A. (1999). Principles and practice of biomass fast pyrolysis processes for liquids. J. Anal. Appl. Pyrolysis 51, 3. doi:10.1016/S0165-2370(99)00005-4

Bridgwater, A. V. (2012). Review of fast pyrolysis of biomass and product upgrading. Biomass Bioenergy 38, 68. doi:10.1016/j.biombioe.2011.01.048

Chen, T., Deng, C., and Liu, R. (2010). Effect of selective condensation on the characterization of bio-oil from pine sawdust fast pyrolysis using a fluidized-bed reactor. Energy Fuels 24, 6616. doi:10.1021/ef1011963

Chen, T., Wu, C., Liu, R., Fei, W., and Liu, S. (2011). Effect of hot vapor filtration on the characterization of bio-oil from rice husks with fast pyrolysis in a fluidizedbed reactor. Bioresour. Technol. 102, 6178. doi:10.1016/j.biortech.2011.02.023

Diebold, J. P., and Czernik, S. (1997). Additives to lower and stabilize the viscosity of pyrolysis oils during storage. Energy Fuels 11, 1081. doi:10.1021/ef9700339

Diebold, J. P., Thermalchemie, I., and Laboratory, N. R. E. (2000). A Review of the Chemical and Physical Mechanisms of the Storage Stability of Fast Pyrolysis Bio-Oils. Golden, CO: National Renewable Energy Laboratory.

Fahmi, R., Bridgwater, A. V., Donnison, I., Yates, N., and Jones, J. M. (2008). The effect of lignin and inorganic species in biomass on pyrolysis oil yields, quality and stability. Fuel 87, 1230. doi:10.1016/j.fuel.2007.07.026

Hilten, R. N., and Das, K. C. (2010). Comparison of three accelerated aging procedures to assess bio-oil stability. Fuel 89, 2741-2749. doi:10.1016/j.fuel.2010.03. 033

Kim, T.-S., Kim, J.-Y., Kim, K.-H., Lee, S., Choi, D., Choi, I.-G., et al. (2012). The effect of storage duration on bio-oil properties. J. Anal. Appl. Pyrolysis 95, 118. doi:10.1016/j.jaap.2012.01.015

Lievens, C., Mourant, D., Gunawan, R., Li, X., and Li, C.-Z. (2013). FT-IR carbonyl bands of bio-oils: importance of water. Fuel 112, 596. doi:10.1016/j.fuel.2012.01. 047

Lievens, C., Mourant, D., He, M., Gunawan, R., Li, X., and Li, C.-Z. (2011). An FT-IR spectroscopic study of carbonyl functionalities in bio-oils. Fuel 90, 3417. doi:10.1016/j.fuel.2011.06.001

Liu, R., Deng, C., and Wang, J. (2009). Fast pyrolysis of corn straw for biooil production in a bench-scale fluidized bed reactor. Energy Sources 32, 10 doi:10.1080/15567030802094037

Liu, R. H., Shen, C. J., Wu, H. J., Deng, C. J., and Liu, S. Y. (2011). Characterisation of bio-oil from fast pyrolysis of rice husk in a fluidised bed reactor. J. Energy Inst. 84, 73. doi:10.1179/014426011X12968328625397

Lu, Q., Zhang, J., and Zhu, X. (2008). Corrosion properties of bio-oil and its emulsions with diesel. Chin. Sci. Bull. 53, 3726. doi:10.1007/s11434-008-0499-7

Marsman, J., Wildschut, J., Evers, P., de Koning, S., and Heeres, H. (2008). Identification and classification of components in flash pyrolysis oil and hydrodeoxygenated oils by two-dimensional gas chromatography and time-of-flight mass spectrometry. J. Chromatogr. A 1188, 17. doi:10.1016/j.chroma.2008.02.034

Mohan, D., Pittman, C. U. Jr., and Steele, P. H. (2006). Pyrolysis of wood/biomass for bio-oil: a critical review. Energy Fuels 20, 848. doi:10.1021/ef0502397

Moreira, N., Valente, L. M., Castro-Cunha, M., Cunha, L. M., and Guedes de Pinho, P. (2013). Effect of storage time and heat processing on the volatile profile of 
Senegalese sole (Solea senegalensis Kaup, 1858) muscle. Food Chem. 138, 2365. doi:10.1016/j.foodchem.2012.11.135

Oasmaa, A., and Kuoppala, E. (2003). Fast pyrolysis of forestry residue. 3. Storage stability of liquid fuel. Energy Fuels 17, 1075. doi:10.1021/ef020206g

Oasmaa, A., Kuoppala, E., Selin, J. F., Gust, S., and Solantausta, Y. (2004). Fast pyrolysis of forestry residue and pine. 4. Improvement of the product quality by solvent addition. Energy Fuels 18, 1578. doi:10.1021/ef040038n

Oasmaa, A., and Meier, D. (2005). Norms and standards for fast pyrolysis liquids: 1. Round robin test. J. Anal. Appl. Pyrolysis 73, 323. doi:10.1016/j.jaap.2005.03.003

Oasmaa, A., Peacocke, C., and Tutkimuskeskus, V. T. (2001). A Guide to Physical Property Characterisation of Biomass-Derived Fast Pyrolysis Liquids. Espoo: Technical Research Centre of Finland.

Pattiya, A., and Suttibak, S. (2012). Production of bio-oil via fast pyrolysis of agricultural residues from cassava plantations in a fluidised-bed reactor with a hot vapour filtration unit. J. Anal. Appl. Pyrolysis 95, 227. doi:10.1016/j.jaap.2012. 02.010

Pidtasang, B., Udomsap, P., Sukkasi, S., Chollacoop, N., and Pattiya, A. (2013). Influence of alcohol addition on properties of bio-oil produced from fast pyrolysis of eucalyptus bark in a free-fall reactor. Ind. Eng. Chem. 19, 1851. doi:10.1016/j.jiec.2013.02.031

Tessarolo, N. S., dos Santos, L. R. M., Silva, R. S. F., and Azevedo, D. A. (2013). Chemical characterization of bio-oils using comprehensive two-dimensional gas chromatography with time-of-flight mass spectrometry. J. Chromatogr. A 1279, 68. doi:10.1016/j.chroma.2012.12.052

Theissen, H. W. (2009). Effects of contamination of biobased hydraulic fluids with mineral oil. J. ASTM Int. 6, 9. doi:10.1520/JAI101598
Vamvuka, D. (2011). Bio-oil, solid and gaseous biofuels from biomass pyrolysis processes - an overview. Int. J. Energy Res. 35, 835. doi:10.1002/er.1804

Wu, X. (2011). Effects of Different Kinds of Additives and Storage Methods on the Stability of Bio-Oil. Shanghai: Jiao Tong University.

Yin, R., Liu, R., Mei, Y., Fei, W., and Sun, X. (2013). Characterization of bio-oil and bio-char obtained from sweet sorghum bagasse fast pyrolysis with fractional condensers. Fuel 112, 96-104. doi:10.1016/j.fuel.2013.04.090

Conflict of Interest Statement: The authors declare that the research was conducted in the absence of any commercial or financial relationships that could be construed as a potential conflict of interest.

Received: 14 November 2013; accepted: 11 January 2014; published online: 27 January 2014.

Citation: Zhang L, Shen C and Liu R (2014) GC-MS and FT-IR analysis of the bio-oil with addition of ethyl acetate during storage. Front. Energy Res. 2:3. doi: 10.3389/fenrg.2014.00003

This article was submitted to Bioenergy and Biofuel, a section of the journal Frontiers in Energy Research.

Copyright (c) 2014 Zhang, Shen and Liu. This is an open-access article distributed under the terms of the Creative Commons Attribution License (CC BY). The use, distribution or reproduction in other forums is permitted, provided the original author (s) or licensor are credited and that the original publication in this journal is cited, in accordance with accepted academic practice. No use, distribution or reproduction is permitted which does not comply with these terms. 